\title{
Differentiation of Three Homogeneous Groups of Rhizoctonia solani Anastomosis Group 4 by Analysis of Fatty Acids
}

\author{
Janell Stevens Johnk and Roger K. Jones
}

Former graduate research assistant and professor, Department of Plant Pathology, University of Minnesota, St. Paul 55108. J. Stevens Johnk is deceased.

Accepted for publication 21 May 2001.

\begin{abstract}
Stevens Johnk, J., and Jones, R. K. 2001. Differentiation of three homogeneous groups of Rhizoctonia solani anastomosis group 4 by analysis of fatty acids. Phytopathology 91:821-830.

Profiles of fatty acids from 70 isolates of Rhizoctonia solani anastomosis group (AG)-4 clustered into three groups, corresponding to homogeneous group (HG)-I, HG-II, and a newly described HG-III. Isolates from Georgia peanuts exhibiting limb rot were characterized as gas chromatography (GC) subgroup 1 (GC-1) and contained HG-I isolates. Isolates from diseased soybean hypocotyls grown in North Dakota and sugar beet seedlings, taproots, and tare soil in Minnesota and North Dakota were characterized as GC subgroup 2 (GC-2) and contained

predominantly HG-II isolates but also included three distinct isolates based on fatty acid methyl ester (FAME) analysis and morphological features. Selected isolates from North Carolina cucumbers clustered into three distinct groups that corresponded to HG-I, HG-II, and the newly described HG-III. Distinct isolates from the soybean and sugar beet populations clustered with HG-III. Fatty acid profiles of AG-4 were compared with FAME library profiles of AG-1, AG-2 type 2, and AG-3, which were developed in previous studies and were sufficiently different that they could be used to support speciation of this group from $R$. solani. It is suggested that binomial $R$. practicola may be appropriate for the portion of AG-4 identified as HG-II.
\end{abstract}

Rhizoctonia solani Kuhn (teleomorph = Thanatephorus cucumeris [A.B. Frank] Donk) contains a diverse grouping of fungi that exhibit a wide and often overlapping range of pathogenicity $(1,3)$. The species has been divided into anastomosis groups (AGs) based on fusion reactions between cell walls of vegetative hyphae $(8,33)$ and further subdivided into intraspecific groups (ISGs) based on cultural morphology and physiological characteristics $(30,31)$. Certain ISGs are ecologically or pathologically specialized as to their primary host or host group, whereas some, such as AG-3, appear to have a limited host range $(3,31)$. Isolate collections characterized as an ISG are recovered frequently in association with specific symptoms of recognizably distinct diseases. Although cross-pathogenicity can usually (but not always) (45) be demonstrated under artificial inoculation, isolation frequency and pathogenicity indices of characterized populations from field studies generally support the concept that ISGs represent natural subspecific groupings of $R$. solani. Recently, Ogoshi (32) suggested that use of the term ISG should be discontinued and the term subgroup be used instead.

AG-4 is one of the most widely recognized causes of diseases incited by $R$. solani (3). To date, AG-4 has not been associated with a specific host or a specialized host range. Isolates of $R$. solani identified as AG-4 cause seed rot, postemergence damping off, limb rot, and root rots of important crop plants including peanut $(7,52)$, soybean $(25,26,29)$, sugar beet $(27,28,51)$, and others $(3,30,31,41)$. Fruit rot (belly rot or soil rot) of cucumber $(18,46)$ is also caused by isolates characterized as AG-4.

Published as paper 991,220,088 of the Scientific Journal Series of the Minnesota Agricultural Experiment Station based on research conducted under project 22-038.

Corresponding author: R. K. Jones; E-mail address: jones014@umn.edu

Publication no. P-2001-0629-01R

(C) 2001 The American Phytopathological Society
Intragroup variation in isolates of $R$. solani AG-4 has been studied. The ability of isolates to sporulate in vitro under defined conditions is variable among isolates of AG-4 (2) as are electrophoretic profiles of soluble proteins $(17,35)$. Polymorphisms have been identified in esterase zymograms (22). DNA-DNA hybridization data suggest that AG-4 is a heterogeneous population, containing identifiable subgroupings $(17,48)$. Two homogeneous groups (HGs), HG-I and HG-II, thought to be genetically divergent (49) have been proposed (17). It is also reported that the HGs can be differentiated based on color of colonies and sclerotia formed on potato dextrose agar (PDA) (41).

Ribosomal DNA sequences of the internal transcribed spacer (ITS) regions of $R$. solani AG-4 have been investigated $(6,16,19)$. Kuninaga et al. (16) examined 15 isolates of AG-4 and found that six isolates of HG-I showed 97.2 to $100 \%$ sequence homogeneity and nine isolates from HG-II had identical sequences $(100 \%$ homology). Sequence homogeneity between HG-I and HG-II in the ITS1 region was 92.3 to $93.7 \%$. Boysen et al. (6) identified three subgroups among 10 isolates of AG-4, based on direct sequencing of asymmetric polymerase chain reaction products of the ITS regions. Virulent isolates from subarid (warm) climates in either Spain or Israel corresponded to HG-I and those from continental (cool) climates in Spain corresponded to HG-II. Two avirulent isolates were identified (Rh2815 from Spain and 521 from Israel) that were distinct from either HG-I or HG-II but similar to each other (6).

Unique whole-cell fatty acid profiles have been used to differentiate certain subgroups within $R$. solani AG-1 (44), AG-2-2 (43), and pathogenically distinct populations in AG-3 affecting potato and tobacco (45). The purpose of this research was to examine the usefulness of fatty acid analysis to differentiate homogeneous groups of isolates in AG-4. Isolates from peanut (10), soybean (29), and sugar beet (51) were investigated. M. A. Cubeta (unpublished data) recently identified three restriction phenotype (RP) groups (RP1, RP2, and RP3) within populations of AG-4 isolated from diseased cucumber in North Carolina. Isolates from 
TABLE 1. Characteristics of isolates of Rhizoctonia solani anastomosis group 4 analyzed in this study

\begin{tabular}{|c|c|c|c|c|c|}
\hline Isolate & Homogeneous group (HG) & Restriction phenotype (RP) & $\begin{array}{l}\text { Fatty acid methyl } \\
\text { ester subgroup }\end{array}$ & Host and origin & Isolate reference (source) ${ }^{\mathrm{z}}$ \\
\hline 4-Pn-070 & HG-I & RP1 & GC-1 & Peanut, GA & Cubeta 159-RS (3) \\
\hline 4-Pn-071 & HG-I & RP1 & GC-1 & Peanut, GA & Cubeta 165-RS (3) \\
\hline 4-Pn-072 & HG-I & RP1 & GC-1 & Peanut, GA & Cubeta 177-RS (3) \\
\hline 4-Pn-073 & HG-I & RP1 & GC-1 & Peanut, GA & Cubeta 188-RS (3) \\
\hline 4-Pn-075 & HG-I & RP1 & GC-1 & Peanut, GA & Cubeta 196-RS (3) \\
\hline 4-Pn-077 & HG-I & RP1 & GC-1 & Peanut, GA & Cubeta 198-RS (3) \\
\hline 4-Pn-079 & HG-I & RP1 & GC-1 & Peanut, GA & Cubeta 211-RS (3) \\
\hline 4-Pn-079 & HG-I & RP1 & GC-1 & Peanut, GA & Cubeta 218-RS (3) \\
\hline 4-Pn-080 & HG-I & RP1 & GC-1 & Peanut, GA & Cubeta 243-RS (3) \\
\hline 4-Pn-086 & HG-I & RP1 & GC-1 & Peanut, GA & Cubeta 247-RS (3) \\
\hline 4-Pn-088 & HG-I & RP1 & GC-1 & Peanut, GA & Cubeta 296-RS (3) \\
\hline 4-Pn-089 & HG-I & RP1 & GC-1 & Peanut, GA & Cubeta 298-RS (3) \\
\hline 4-Pn-090 & HG-I & RP1 & GC-1 & Peanut, GA & Cubeta 309-RS (3) \\
\hline 4-Pn-091 & HG-I & RP1 & GC-1 & Peanut, GA & Cubeta 311-RS (3) \\
\hline 4-Pn-092 & HG-I & RP1 & GC-1 & Peanut, GA & Cubeta 359-RS (3) \\
\hline 4-Sy-006 & HG-II & $\mathrm{RP} 2$ & GC-2 & Soybean, ND & Nelson 35 Rhi (6) \\
\hline 4-Sy-007 & HG-II & $\mathrm{RP} 2$ & GC-2 & Soybean, ND & Nelson 39-2 (6) \\
\hline 4-Sy-008 & HG-II & $\mathrm{RP} 2$ & GC-2 & Soybean, ND & Nelson 45-3 (6) \\
\hline 4-Sy-009 & HG-II & $\mathrm{RP} 2$ & GC-2 & Soybean, ND & Nelson 47-6 (6) \\
\hline 4-Sy-010 & HG-II & $\mathrm{RP} 2$ & GC-2 & Soybean, ND & Nelson 74-3 (6) \\
\hline 4-Sy-011 & HG-II & RP2 & GC-2 & Soybean, ND & Nelson 82-1 (6) \\
\hline 4-Sy-012 & HG-II & $\mathrm{RP} 2$ & GC-2 & Soybean, ND & Nelson 85-1 (6) \\
\hline 4-Sy-013 & HG-III & RP3 & GC-3 & Soybean, ND & Nelson 89-3 (6) \\
\hline 4-Sy-014 & HG-II & $\mathrm{RP} 2$ & GC-2 & Soybean, ND & Nelson 90-1 (6) \\
\hline 4-Sy-015 & HG-II & $\mathrm{RP} 2$ & GC-2 & Soybean, ND & Nelson 91-1 (6) \\
\hline 4-Sy-016 & HG-II & $\mathrm{RP} 2$ & GC-2 & Soybean, ND & Nelson 91-2 (6) \\
\hline 4-Sy-017 & HG-II & RP2 & GC-2 & Soybean, ND & Nelson 33-5 (6) \\
\hline 4-Sy-018 & HG-II & RP2 & GC-2 & Soybean, ND & Nelson Sin-1 (6) \\
\hline 4-Sy-019 & HG-II & $\mathrm{RP} 2$ & GC-2 & Soybean, ND & Nelson Sy9-1 (6) \\
\hline 4-Sy-020 & HG-II & $\mathrm{RP} 2$ & GC-2 & Soybean, ND & Nelson SS7-3 (6) \\
\hline 4-Sb-022 & HG-II & $\mathrm{RP} 2$ & GC-2 & Sugar beet, MN & Windels 90-19-8C (7) \\
\hline $4-\mathrm{Sb}-023$ & HG-II & RP2 & GC-2 & Sugar beet, MN & Windels Py-10-16 (7) \\
\hline $4-\mathrm{Sb}-027$ & HG-II & $\mathrm{RP} 2$ & GC-2 & Sugar beet, MN & Windels 90-20-13 (7) \\
\hline 4-Sb-029 & HG-II & $\mathrm{RP} 2$ & GC-2 & Sugar beet, MN & Windels 90-19-10D (7) \\
\hline 4-Sb-030 & HG-II & $\mathrm{RP} 2$ & GC-2 & Sugar beet, ND & Windels $2-21-\mathrm{T}(7)$ \\
\hline 4-Sb-031 & HG-II & $\mathrm{RP} 2$ & GC-2 & Sugar beet, ND & Windels FS-87-14-6 (7) \\
\hline 4-Sb-033 & HG-II & RP2 & GC-2 & Sugar beet, MN & Windels 6-4-T (7) \\
\hline 4-Sb-037 & HG-III & RP3 & GC-3 & Sugar beet, ND & Windels 90-36-48 (7) \\
\hline 4-Sb-038 & HG-III & RP3 & GC-3 & Sugar beet, ND & Windels 90-19-8A (7) \\
\hline 4-Sb-042 & HG-II & RP2 & GC-2 & Sugar beet, ND & Windels Py-2-30 (7) \\
\hline 4-Sb-043 & HG-II & $\mathrm{RP} 2$ & GC-2 & Sugar beet, ND & Windels 89-18-9 (7) \\
\hline 4-Sb-044 & HG-II & $\mathrm{RP} 2$ & GC-2 & Sugar beet, MN & Windels 85-3-6R (7) \\
\hline 4-Sb-047 & HG-II & $\mathrm{RP} 2$ & GC-2 & Sugar beet, ND & Windels $1-13-5(7)$ \\
\hline 4-Sb-048 & HG-II & RP2 & GC-2 & Sugar beet, ND & Windels 3-T-5 (7) \\
\hline 4-Sb-049 & HG-II & RP2 & GC-2 & Sugar beet, MN & Windels $18-\mathrm{T}-8 \mathrm{~B}(7)$ \\
\hline $4-0-002$ & HG-II & $\mathrm{RP} 2$ & GC-2 & Conifer, CA & Butler $283(5)$ \\
\hline $4-0-003$ & HG-I & RP1 & GC-1 & Smell melon, TX & Jones HJOT (5) \\
\hline $4-0-004$ & HG-II & RP2 & GC-2 & Sugar beet, Japan & Ogoshi RH-165 (7) \\
\hline $4-0-005$ & HG-II & $\mathrm{RP} 2$ & GC-2 & Alfalfa, MN & Anderson 140 (1) \\
\hline 4-Po-064 & HG-II & $\mathrm{RP} 2$ & GC-2 & Potato, ND & Gudmestad R1124 (4) \\
\hline 4-Po-065 & HG-II & $\mathrm{RP} 2$ & GC-2 & Potato, ND & Gudmestad R1125 (4) \\
\hline 4-Po-066 & HG-II & $\mathrm{RP} 2$ & GC-2 & Potato, ND & Gudmestad R1126 (4) \\
\hline 4-Po-067 & HG-II & $\mathrm{RP} 2$ & GC-2 & Potato, ND & Carling P16 (2) \\
\hline 4-Po-068 & HG-II & $\mathrm{RP} 2$ & GC-2 & Potato, ND & Carling P26 (2) \\
\hline 4-Po-068 & HG-II & $\mathrm{RP} 2$ & GC-2 & Potato, ND & Carling P35 (2) \\
\hline 4-0-095 & HG-I & RP1 & GC-1 & Peanut, Japan & ATCC $76126(3)$ \\
\hline 4-Cu-096 & HG-I & RP1 & GC-1 & Cucumber, NC & Cubeta 393-RS (3) \\
\hline 4-Cu-097 & HG-I & RP1 & GC-1 & Cucumber, NC & Cubeta 440-RS (3) \\
\hline 4-Cu-098 & HG-I & RP1 & GC-1 & Cucumber, NC & Cubeta 441-RS (3) \\
\hline 4-Cu-100 & HG-I & RP1 & GC-1 & Cucumber, NC & Cubeta 434-RS (3) \\
\hline $4-0-101$ & HG-II & $\mathrm{RP} 2$ & GC-2 & Alfalfa, MN & ATCC $44662(3)$ \\
\hline 4-Cu-102 & HG-II & $\mathrm{RP} 2$ & GC-2 & Cucumber, NC & Cubeta 396-RS (3) \\
\hline 4-Cu-103 & HG-II & $\mathrm{RP} 2$ & GC-2 & Cucumber, NC & Cubeta 397-RS (3) \\
\hline 4-Cu-105 & HG-II & RP2 & GC-2 & Cucumber, NC & Cubeta 407-RS (3) \\
\hline 4-Cu-108 & HG-II & $\mathrm{RP} 2$ & GC-2 & Cucumber, NC & Cubeta 418-RS (3) \\
\hline 4-0-109 & HG-III & RP3 & GC-3 & Table beet, MD & ATCC 14007 (3) \\
\hline 4-Cu-111 & HG-III & RP3 & GC-3 & Cucumber, NC & Cubeta 437-RS (3) \\
\hline 4-Cu-112 & HG-III & RP3 & GC-3 & Cucumber, NC & Cubeta 438-RS (3) \\
\hline 4-Cu-113 & HG-III & RP3 & GC-3 & Cucumber, NC & Cubeta 439-RS (3) \\
\hline 4-Cu-116 & HG-III & RP3 & GC-3 & Cucumber, NC & Cubeta 446-RS (3) \\
\hline
\end{tabular}

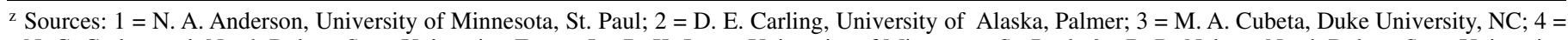
N. C. Gudmestad, North Dakota State University, Fargo; $5=$ R. K. Jones, University of Minnesota, St. Paul; $6=$ B. D. Nelson, North Dakota State University, Fargo; and 7 = C. E. Windels, University of Minnesota, NWROC, Crookston. 
these populations characterized based on rDNA RP $(9,10,49)$ were included in this study. Analysis of AG-4 is compared with previously published analyses of AG-1, AG-2-2, and AG-3, and newly presented data from AG-2-1 and the taxonomic implications of these results are discussed.

\section{MATERIALS AND METHODS}

Source of isolates. We compared fatty acid compositions of 45 isolates from populations of $R$. solani AG-4 recovered from peanut, soybean, and sugar beet (Table 1). Isolates from peanut were derived from diseased plants in Georgia and were characterized as HG-I, based on rDNA RP by Cubeta et al. (10). Isolates from soybean were collected from diseased soybean hypocotyls in fields located in the Red River Valley of Minnesota and North Dakota (29). Isolates from sugar beet were recovered from symptomatic seedlings or taproots of sugar beet or from tare soil of sugar beet fields located in the Red River Valley of Minnesota and North Dakota (51). RP determinations of rDNA for the soybean and sugar beet isolates were conducted by M. A. Cubeta and are presented in Table 1. In order to develop an HG library, 12 isolates recovered from diseased cucumber in North Carolina were analyzed for fatty acids and compared. Cucumber isolates were selected to equally represent the three rDNA phenotypes (four isolates each), and isolates representing the RP- tester strains of Cubeta were included in developing the AG-4 HG library. They were 4-0-095 (ATCC 76126) from peanut in Japan (HG-I, RP1), 4-0-101 (ATCC 44662) from alfalfa in Minnesota (HG-II, RP2), and 4-0-109 (ATCC 14007) from Maryland field soil baited with table beet seed (HG-III, RP3). The following anastomosis-tester isolates were also analyzed: Butler 283 from conifer in California (4-0-002), Ogoshi Rh-165 recovered from sugar beet in Japan (4-0-004), and Anderson 140 recovered from alfalfa in Minnesota (4-0-005). Six isolates, recovered from potatoes grown in North Dakota and identified as $R$. solani AG-4, were included to determine their HG affinity (Table 1). RP determinations for the potato isolates and the AG-tester isolates were conducted by Cubeta and are presented in Table 1. All isolates were maintained on PDA (Difco Laboratories, Detroit) amended with $50 \mathrm{mg} / \mathrm{liter}$ each of streptomycin sulfate and penicillin G (PDA+).

Cultural appearance and hyphal features. Cultural characteristics of isolates were determined on PDA+. Cultures were incubated at $28^{\circ} \mathrm{C}$ in the dark and were evaluated for colony color, zonation, production of diffusible pigments, and formation and color of sclerotia at 4, 10, and 14 days. Duplicate cultures were incubated at $25^{\circ} \mathrm{C}$ under a light table illuminated with a $12 \mathrm{~h}$ day/ $12 \mathrm{~h}$ night photoperiod. The nuclear condition in young, vegetative hyphae was determined by the DAPI $\left(4^{\prime}, 6\right.$-diamidino-2phenylindole) stain technique (14). The diameter of the vegetative hyphae was measured, and nuclei in 20 cells each from nine isolates (three in each of three homogeneous groups) were examined and counted (Table 2). An isolate of AG-2-1 (ATCC 4468) was included as a comparison standard.

Cellular fatty acid analysis. The Microbial Identification System (MIS; Microbial ID Inc., Newark, DE) was employed to analyze samples. Cultures were grown on PDA+ at $28^{\circ} \mathrm{C}$ in the dark for 4 days. A 32- $\mathrm{cm}^{2}$ mycelial mat was removed, weighed, and analyzed with gas chromatography (GC) as previously described (42). Fatty acid methyl ester (FAME) compositions were determined by the TSBA peak naming table (version 3.6, Microbial ID). Each extraction and analysis was performed twice with three replicates per run. Analysis of variance (ANOVA; SAS Institute, Cary, NC) was performed on percent FAME compositions. Mean separation was accomplished by the Waller-Duncan K-ratio $t$ test $(\mathrm{K}=100 ; P=0.05)$. Principle component analysis (SAS Institute) was performed on mean percent FAME compositions.

Library generation. Library Generation software (Microbial ID) was employed to develop two types of fatty acid libraries: an isolate library or a population library. Isolate library entries, used to compare isolates within a population of $R$. solani AG-4, were based on the mean percent composition of six replicate samples of that isolate. Fatty acids used to create an isolate entry were required to be reproducibly detectable in the isolate by employing a quality threshold value of 0.25 (42). Relative similarities among isolate library entries were determined by cluster analysis. A resemblance matrix based on Euclidian-distance coefficients was computed from the pairwise comparisons of each isolate entry, with every other isolate entry based on qualitative and quantitative differences in FAME composition. A dendrogram was constructed by the unweighted pair-group method with arithmetic averages, and Euclidean distance was used to portray the degree of relatedness. Dendrograms were constructed to compare 12 isolate library entries from cucumber and the RP-tester strains from each group: RP1 = 4-0-095, RP2 = 4-0-101, and RP3 = 4-0-109 (Table 1).

Host population library entries were developed for analyzed samples of isolates that had been collected from diseased peanut (4-Pn), soybean (4-Sy), and sugar beet (4-Sb) for comparisons of these populations. Each entry in the population library represented the mean fatty acid composition of 90 samples (15 isolates per population with six replicate samples per isolate). Principal component analysis was used to examine the relationships among the 45 isolates, and dendrograms were constructed by cluster analysis to compare the relationships between the three host population library entries.

An HG population library was developed from samples of the three RP-tester strains and 12 selected isolates from cucumber (Table 1). The library entries (HG-I, HG-II, and HG-III) were each derived from 30 samples. Each HG entry included replicate samples of four selected isolates from cucumber and the respective RP-tester strain. Samples of AG-4 isolates from potato (Table 1) and of all AG-tester isolates were challenged against this HG population library to determine their HG affinity. The output of each sample report includes a similarity index (value between 0.0 and 1.0) that expresses how well the profile of that sample matches the population library entry (42). This index reflects the Gaussian distance of the samples (distance in $n$-dimensional space) from the mean profile of the closest population library entry.

The 90 samples of AG-4 used to create the HG library were futher combined with samples of AG-1, AG-2-2, and AG-3 (from previously published studies) to develop a species library of $R$. solani. A library entry for AG-2 type 1 (AG-2-1) was developed from 20 isolates (120 samples) of AG-2-1 that had been analyzed with the same method and is included in this comparison. A dendrogram was constructed by cluster analysis to compare the relationships between 15 subspecific or intraspecific library entries of $R$. solani AGs 1 to 4 , as characterized in this report or in prior publications (43-45).

TABLE 2. Hyphal width and nuclei per cell in isolates of Rhizoctonia solani anastomosis group (AG)-4

\begin{tabular}{|c|c|c|c|c|}
\hline \multirow[b]{2}{*}{ AG-isolate } & \multirow{2}{*}{$\begin{array}{l}\text { Homogeneous } \\
\text { group (HG) }\end{array}$} & \multirow{2}{*}{$\begin{array}{l}\text { Hyphal } \\
\text { width }\end{array}$} & \multicolumn{2}{|c|}{ Nuclei/cellz } \\
\hline & & & Mean & Mode \\
\hline 4-0-003 & HG-I & $7.2 \mathrm{a}$ & $4.2 \mathrm{a}$ & 4 \\
\hline 4-0-095 & HG-I & $7.1 \mathrm{a}$ & $4.2 \mathrm{a}$ & 4 \\
\hline 4-Pn-070 & HG-I & $7.3 \mathrm{a}$ & $4.0 \mathrm{a}$ & 4 \\
\hline 4-0-004 & HG-II & $6.7 \mathrm{a}$ & $4.2 \mathrm{a}$ & 4 \\
\hline 4-0-005 & HG-II & $6.8 \mathrm{a}$ & $4.1 \mathrm{a}$ & 4 \\
\hline $4-\mathrm{Sb}-022$ & HG-II & $6.9 \mathrm{a}$ & $4.1 \mathrm{a}$ & 4 \\
\hline 4-0-109 & HG-III & $6.7 \mathrm{a}$ & $3.7 \mathrm{a}$ & 4 \\
\hline 4-Sy-013 & HG-III & $7.0 \mathrm{a}$ & $4.2 \mathrm{a}$ & 4 \\
\hline $4-\mathrm{Sb}-037$ & HG-III & $6.5 \mathrm{a}$ & $4.2 \mathrm{a}$ & 4 \\
\hline $2-1-008$ & & & & \\
\hline (ATCC 44658) & & $9.8 \mathrm{~b}$ & $8.6 \mathrm{~b}$ & 8 \\
\hline
\end{tabular}

${ }^{\mathrm{z}}$ Hyphal width and nuclear numbers determined in 20 cells of young vegetative growth of isolates on potato dextrose agar at $28^{\circ} \mathrm{C}$. Values in the same column followed by the same letter are not statistically different $(P=0.05)$. 


\section{RESULTS}

Cultural appearance. At 4 days after dark incubation on PDA+, cultures isolated from peanut were buff brown (36) with no zonation or pigmentation of the agar. Mycelial growth was slightly aerial to aerial. By 14 days, colony color darkened to snuff brown (36), and diffusible pigments were observed. Sclerotial production was not obvious (Fig. 1).

At 4, 10, and 14 days after inoculation, there was a marked similarity in cultural appearance among most isolates from soybean, sugar beet, potato, and the AG-4 anastomosis-tester isolates 4-0-004 and 4-0-005 (Table 1). At 4 days, cultures incubated in the dark were white with no zonation or pigmentation of the agar. After 14 days, cultures became pale, drab gray (35). Mycelial growth was appressed, mealy, and matlike. Darkincubated cultures lacked zonation, but zonation was present in cultures incubated under lights with a 12-h photoperiod (Fig. 1). Pigmentation of the agar was moderate, variable, and increased over time. Sclerotia were absent at 4 days but occasionally a few did develop by 14 days, and were scattered over the culture. At $28^{\circ} \mathrm{C}$, isolates of HG-II grew slower than isolates of HG-I.

Cultures isolated from cucumber and classified as RP3 were olive buff (36), and mycelial growth was appressed to slightly aerial. After 10 days, cultures incubated under lights developed concentric bands or zones of olive-brown sclerotia on PDA+ (Fig. 1). When incubated in darkness, isolates classified as RP3 were white with buff brown (36) hyphae developing radially from the cultures center (Fig. 1). Diffusible pigments were not obvious in this group at 4,10 , or 14 days. Isolate $4-\mathrm{Sy}-013$ (from soybean) and isolates 4-Sb-037 and 4-Sb-038 (from sugar beet) were similar in appearance to RP3 isolates, containing slightly more (brown) diffusible pigment than the cucumber isolates but exhibiting characteristic zones of sclerotia in bands around the culture perimeter. RP-tester isolates (RP1, RP2, and RP3) had culture appearances similar to other isolates in their respective groups. At both 4 and 14 days, isolates recovered from cucumber and classified as RP1 were similar in appearance to the RP1 cultures from peanut. At both 4 and 14 days, cultures isolated from cucumber and classified as RP2 were similar in appearance to the HG-II isolates from soybean and sugar beet.

Hyphal features. Young, vegetative hyphae of AG-4 isolates contained 3 to 6 nuclei per cell with a mean of 4.1 and a mode of 4 (Table 2). There were no significant differences $(P=0.05)$ between isolates of the three HGs. The diameter of young, vegetative cells in isolates of AG-4 averaged $6.9 \mu$, and all isolates were significantly $(P=0.05)$ narrower than the isolate of AG-2-1 (ATCC 44658) included for comparison (Table 2).

Cellular fatty acid analysis. Fifteen fatty acids were consistently present in 4-day-old cultures of isolates of $R$. solani AG-4 representing populations from peanut, soybean, and sugar beet (Table 3). Three of these fatty acids (linoleic-18:2 cis 9,12; oleic-18:1 cis 9; and palmitic-16:0) comprised 93.5 to $95.1 \%$ of the cellular fatty acids identified. Fatty acids present in smaller amounts included: myristic (14:0), pentadecanoic (15:0), 2-hydroxypalmitic (16:0 $2 \mathrm{OH})$, palmitoleic (16:1 cis 9), 9-hexadecenoic (16:1 trans 9), heptadecanoic (17:0), 15-methylheptadecanoic (17:0a), 9-heptadecanoic (17:1 cis 9), stearic (18:0), the dimethylacetyl derivative of 11-octadecenoic (18:1 cis dma), arachidoic (20:0), and an unknown fatty acid with an equivalent chain length (ECL) of 18.201 (42). ANOVA showed no effect of experimental runs (run 1 versus run 2) on fatty acid composition. Therefore, data were combined for further statistical analysis.

Although the fatty acid compositions of the isolates were qualitatively similar, quantitative differences were observed. ANOVA indicated that there were significant differences $(P=0.001)$ among isolates. ANOVA followed by mean separation, using the WallerDuncan K-ratio $t$ test, indicated that there was a significant difference $(P=0.05)$ between the population from peanut and populations from either soybean or sugar beet in 13 of 15 detected fatty acids (Table 3). Mean separation tests also revealed significant differences $(P=0.05)$ between each of the three HGs (HG-I, HG-II, and HG-III) in 12 of 14 FAMES using population libraries derived from the cucumber isolates and their respective RP-tester strains (Table 4). Hexadecenoic acid (16:1 trans 9) was not identified in these samples.

Principle component analysis with all 15 detected fatty acids showed a close relationship between HG-II isolates from soybean and HG-II isolates from sugar beet and indicated that HG-I isolates from peanut were distinct (data not shown). In this analysis, samples of the brown soybean isolate (4-Sy-013) clustered with the peanut isolates and samples of sugar beet isolates 4-Sb-037 and 4-Sb-038 (which clustered together) were intermediate between the HG-I and HG-II isolates. These isolates were subsequently found to belong to HG-III.

Library generation and validation. A fatty acid library entry was created for populations from peanut (4-Pn), soybean (4-Sy), and sugar beet (4-Sb). Eight fatty acids were reproducibly detected (quality threshold $=0.25$ ). The following eight fatty acids were used in the creation of all three population library entries: $14: 0 ; 15: 0 ; 16: 1$ cis $9 ; 16: 0 ; 17: 1$ cis $9 ; 18: 2$ cis 9,$12 ; 18: 1$ cis 9 ; and 18:0 (Table 3). A dendrogram of the population library entries from soybean and sugar beet indicated a close relationship between these populations (Euclidean distance of 2.15). These populations clustered with the peanut population at a Euclidean distance of 8.73. Omitting the HG-III isolates (4-Sy-013, 4-Sb037, and 4-Sb-038) reduced the Euclidian distance between 4-Sy and 4-Sb population entries to 1.47 and increased the distance between these groups and the 4-Pn entry to 9.97 (Fig. 2).

A fatty acid library entry was created for each of the HGs within the cucumber isolate collection. Eight of fifteen fatty acids were reproducibly detected and met the quality threshold criteria. The following eight fatty acids were used in the creation of three HG population library entries: $14: 0 ; 15: 0 ; 16: 1$ cis $9 ; 16: 0 ; 17: 1$ cis $9 ; 18: 2$ cis 9,$12 ; 18: 1$ cis 9 ; and 18:0. The fatty acid 20:0 was reproducibly detected in isolates belonging to the HG-I cucumber population and was used to generate the GC-1 library entry. A dendrogram of the cucumber isolates and their respective RPtester strains showed clustering among isolates of the same HG and differences between each of the three groups (Fig. 3). Isolates of HG-I and HG-III clustered with a Euclidean distance of 6.95, whereas isolates of HG-II clustered with the other groups at a Euclidean distance of 10.18.

Similarity indices of peanut samples challenged against the $\mathrm{HG}$ library classified these samples as HG-I (range $=0.85$ to 0.98 ). Similarity indices classified 14 of 15 soybean isolates and 13 of 15 sugar beet isolates as HG-II (range $=0.86$ to 0.98 ). The similarity indices of isolates 4-Sy-013, 4-Sb-037, and 4-Sb-038 classified these samples as HG-III (range $=0.83$ to 0.94 ). The similarity indices of samples from six isolates of AG-4 obtained from potato classified these samples as HG-II (mean $=0.88$; range $=0.81$ to 0.93 ). Similarity indices classified all samples of the three AG-tester isolates as HG-II. Isolate 4-0-003, originally recovered from Cucumis melo in Texas, was classified as HG-I. This isolate was phenotypiclly similar to other HG-I isolates and was characterized as RP1 by Cubeta (Table 1).

Principle component analysis showed a distinct relationship between isolates of the three HGs (HG-I, HG-II, and HG-III) developed from the cucumber isolates and their respective RPtester strains (Fig. 4). AG-tester isolates 4-0-002, 4-0-004, and 4-0-005 clustered with isolates of HG-II in this analysis.

Isolates in the AG-4 HG library were combined to create an AG-4 library entry. When cluster analysis was used to examine the relationship between AG-4 and AG-1, AG-2-2, and AG-3 (4345), AG-4 was found to cluster with the other three AGs at a Euclidean distance of 8.2. To complete the comparison, 20 isolates 
of AG-2-1 (Table 5) were analyzed and a library entry was developed. The AG-2-1 entry more closely pair-matched with AG4 than with AG-2-2 or any of the other subgroups (Fig. 5). The AG-2-1 isolates used in the creation of this library entry were of diverse origins (Table 5). Subgroupings within this collection of AG-2-1 isolates were not identifiable, except five isolates from sugar beet seedlings in Minnesota (2-1-002 through 2-1-006) clustered together.

\section{DISCUSSION}

The fatty acid compositions of isolates of $R$. solani AG-4 from soybean (14 of 15 isolates) and sugar beet (13 of 15 isolates) were very similar, indicated by principle component analysis and cluster analysis. These isolates were drab gray and velvety in PDA+ culture and belong to the same HG (HG-II). These isolates were distinct from the peanut population (HG-I) in cultural appearance

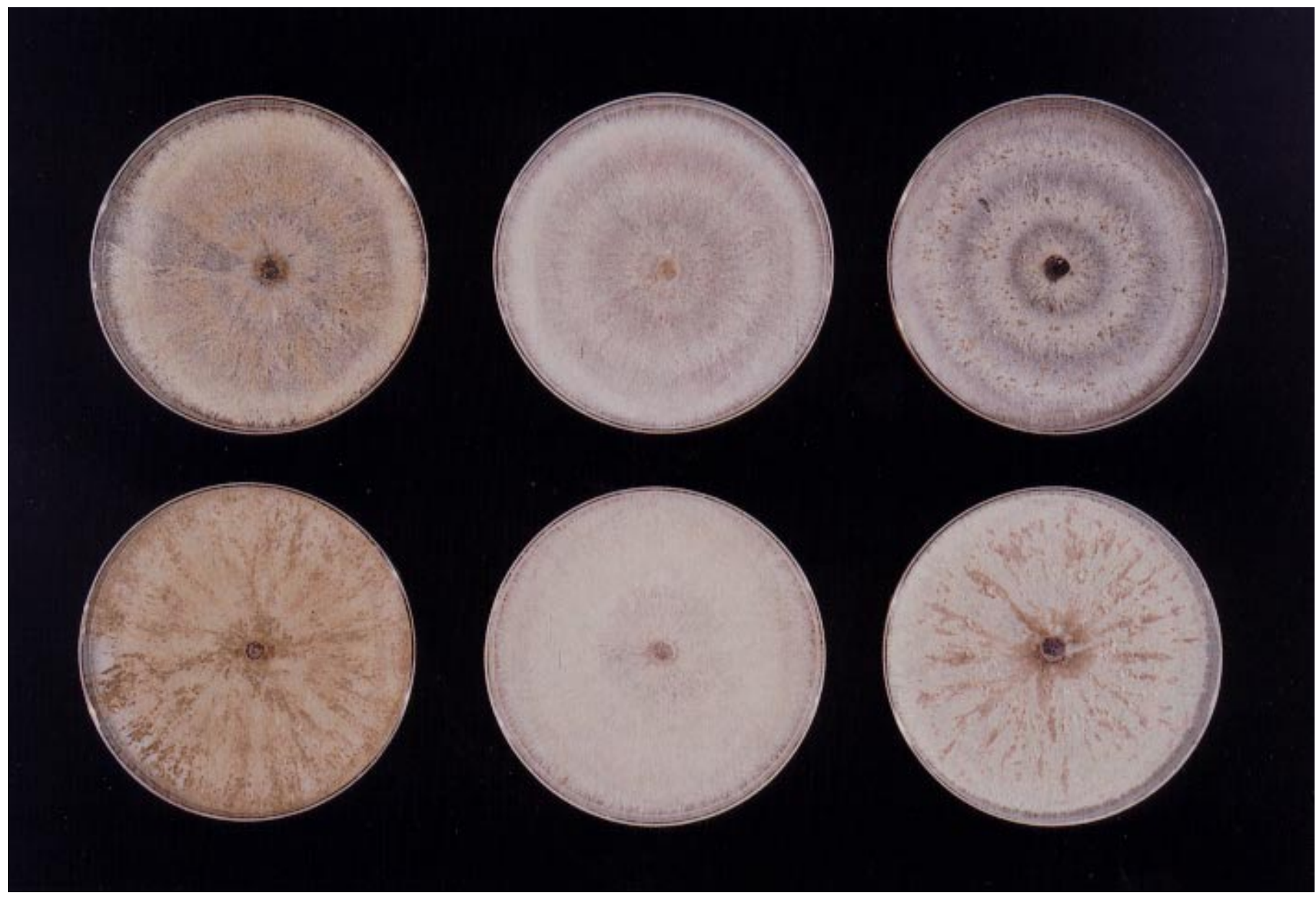

Fig. 1. Cultures of Rhizoctonia solani anastomosis group 4 after 10 days incubation on potato dextrose agar under lights at $25^{\circ} \mathrm{C}$ (top row) and in the dark at $28^{\circ} \mathrm{C}$ (Bottom row). Left, isolate 4-0-095 (HG-I); center, isolate 4-0-101 (HG-II); and right, isolate 4-0-109 (HG-III).

TABLE 3. Percent composition of cellular fatty acids identified in populations of Rhizoctonia solani anastomosis group (AG)-4 isolated from peanut, soybean, and sugar beet ${ }^{2}$

\begin{tabular}{|c|c|c|c|c|c|c|c|c|c|c|c|c|c|c|c|}
\hline & 14:0 & $15: 0$ & $\begin{array}{l}16: 1 \\
\text { cis } 9\end{array}$ & $\begin{array}{c}16: 1 \\
\text { trans } 9\end{array}$ & 16:0 & 17:0a & $\begin{array}{l}17: 1 \\
\text { cis } 9\end{array}$ & 17:0 & $\begin{array}{c}16: 0 \\
2 \mathrm{OH}\end{array}$ & $\begin{array}{c}18: 2 \\
\text { cis } 9,12\end{array}$ & $\begin{array}{l}18: 1 \\
\text { cis } 9\end{array}$ & 18:0 & $\begin{array}{c}\text { ECL } \\
18.201 \\
\end{array}$ & $\begin{array}{c}18: 1 \\
\text { cis } 11\end{array}$ & 20:0 \\
\hline Pear & $31 \mathrm{c}$ & $7 \mathrm{c}$ & 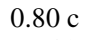 & 0.06 & $11.79 \mathrm{a}$ & $0.09 \mathrm{a}$ & $0.42 \mathrm{c}$ & $0.15 \mathrm{a}$ & $0.18 \mathrm{~b}$ & 62.7 & 18. & $3.57 \mathrm{a}$ & $0.10 \mathrm{a}$ & $0.07 \mathrm{a}$ & $0.15 \mathrm{a}$ \\
\hline Soybean & $0.35 \mathrm{~b}$ & $1.10 \mathrm{~b}$ & $1.05 \mathrm{~b}$ & $0.02 \mathrm{~b}$ & $10.12 \mathrm{~b}$ & $0.06 \mathrm{~b}$ & $0.50 \mathrm{~b}$ & $0.14 \mathrm{a}$ & $0.10 \mathrm{c}$ & $69.21 \mathrm{~b}$ & $15.79 \mathrm{~b}$ & $1.46 \mathrm{~b}$ & $0.00 \mathrm{~b}$ & $0.00 \mathrm{~b}$ & $0.00 \mathrm{~b}$ \\
\hline
\end{tabular}

${ }^{\mathrm{z}}$ Mean of 15 isolates with six replicate extractions grown on potato-dextrose agar for 4 days at $28^{\circ} \mathrm{C}$. Values in each column followed by different letters are significantly different according to Waller-Duncan K-ratio $t$ test $(P=0.05)$.

TABLE 4. Percent composition of cellular fatty acids in homogeneous groups (HG) of Rhizoctonia solani anastomosis group (AG)-4 isolated from cucumber ${ }^{\mathrm{Z}}$

\begin{tabular}{|c|c|c|c|c|c|c|c|c|c|c|c|c|c|c|c|}
\hline & $14: 0$ & $15: 0$ & $\begin{array}{l}16: 1 \\
\text { cis } 9\end{array}$ & $\begin{array}{c}16: 1 \\
\text { trans } 9\end{array}$ & $16: 0$ & $17: 0 \mathrm{a}$ & $\begin{array}{l}17: 1 \\
\text { cis } 9\end{array}$ & 17:0 & $\begin{array}{c}16: 0 \\
2 \mathrm{OH}\end{array}$ & $\begin{array}{c}18: 2 \\
\text { cis } 9,12\end{array}$ & $\begin{array}{l}18: 1 \\
\text { cis } 9\end{array}$ & 18:0 & $\begin{array}{c}\text { ECL } \\
18.201\end{array}$ & $\begin{array}{c}18: 1 \\
\text { cis } 11\end{array}$ & $20: 0$ \\
\hline HG-I & $0.35 \mathrm{a}$ & $0.54 \mathrm{c}$ & $0.84 \mathrm{c}$ & $0.00 \mathrm{a}$ & $12.59 \mathrm{a}$ & $0.08 \mathrm{~b}$ & $0.42 \mathrm{~b}$ & $0.17 \mathrm{~b}$ & $0.15 \mathrm{c}$ & $61.59 \mathrm{~b}$ & $19.02 \mathrm{~b}$ & $3.88 \mathrm{a}$ & $0.07 \mathrm{~b}$ & $0.00 \mathrm{c}$ & $0.29 \mathrm{a}$ \\
\hline HG-II & $0.29 \mathrm{~b}$ & $1.02 \mathrm{~b}$ & $0.89 \mathrm{~b}$ & $0.00 \mathrm{a}$ & $10.04 \mathrm{c}$ & $0.11 \mathrm{a}$ & $0.58 \mathrm{a}$ & $0.22 \mathrm{a}$ & $0.21 \mathrm{a}$ & $67.85 \mathrm{a}$ & $16.86 \mathrm{c}$ & $1.54 \mathrm{c}$ & $0.17 \mathrm{a}$ & $0.08 \mathrm{a}$ & $0.17 \mathrm{~b}$ \\
\hline HG-III & $0.27 \mathrm{c}$ & $0.50 \mathrm{c}$ & $1.25 \mathrm{a}$ & $0.00 \mathrm{a}$ & $10.89 \mathrm{~b}$ & $0.05 \mathrm{c}$ & $0.37 \mathrm{c}$ & $0.12 \mathrm{c}$ & $0.16 \mathrm{~b}$ & $58.46 \mathrm{c}$ & $25.63 \mathrm{a}$ & $2.27 \mathrm{~b}$ & $0.09 \mathrm{~b}$ & $0.04 \mathrm{~b}$ & $0.02 \mathrm{c}$ \\
\hline
\end{tabular}

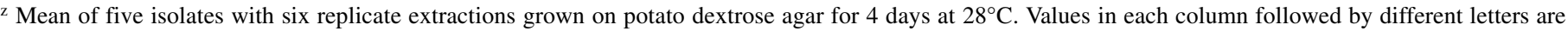
significantly different according to Waller-Duncan K-ratio $t$ test $(P=0.05)$. 
(primarily color; gray versus brown) and could be differentiated from them by FAME analysis.

Vilgalys and Cubeta (personal communication; 49) have suggested that AG-4 may consist of three groups (HG-I, HG-II, and HG-III) based on rDNA restriction analysis. Fatty acid analysis was able to differentiate these three HGs within the cucumber isolate collection by cluster analysis and principle component analysis. RP-tester strains clustered with their appropriate group in this analysis. One isolate from soybean (4-S-013) and two isolates from sugar beet (4-Sb-037 and 4-Sb-038) were more closely related to the newly described HG-III. This relationship is further supported by the unique cultural appearance of these isolates (sclerotial formation pattern) and their rDNA RP. To our knowledge, this is the first report of HG-III isolates in the Upper Midwest.

As a result of their wide host range, isolates of AG-4 are considered the most important AG in the north central region of the United States (3). Constant differences in vegetative features and basidial morphology have led many to place AG-4 in the species $R$. practicola Kotila (teleomorph $=T$. practicola [Kotila] Flentje). T. practicola has been distinquished from $T$. cucumeris by having longer sterigmata and smaller basidiospores, the frequency of basidia with three rather than four sterigmata and the presence of racemose or subracemose branching of the metabasidia $(11,15) . R$. practicola can be distinquished from $R$. solani by its relatively narrow vegetative hyphae, possessing, on average, 4 nuclei per cell, and its comparatively dense growth habit with few sclerotia produced in culture $(3,11-13,15,24,40)$. Critical isolates in these studies conform to $R$. practicola as originally described by Kotila (15) but, more specifically, they conform to HG-II (RP2) and not to all of AG-4. Difficulties in fruiting isolates that clearly belong to HG-I (2) and the paucity of isolates studied in HG-III may have contributed to these subgroups being less recognized in the past. AG-tester isolates, distributed throughout the world by N. A. Anderson (University of Minnesota), E. E. Butler (University of California, Davis), and A. Ogoshi (Hokkaido University), appropriately contained isolates of the "practicola-type" (HG-II) as their representatives of AG-4 (Table 1). Representatives of HGI and HG-III were not included in any of these AG tester sets. However, ATCC 14007 (Papaviza's R-5, an HG-III isolate) has been used by some workers.

\section{Euclidean Distance}

\begin{tabular}{|c|c|c|c|c|c|c|c|}
\hline Host & Entry ID's & 0.0 & 2.0 & 4.0 & 6.0 & 8.0 & 10.0 \\
\hline
\end{tabular}

$\begin{array}{ll}\text { Peanut } & \text { AG-4 Pn (HG-I) } \\ \text { Soybean } & \text { AG-4 Sy (HG-II) } \\ \text { Sugar beet } & \text { AG-4 Sb (HG-II) }\end{array}$

Fig. 2. Dendrogram of population library entries of Rhizoctonia solani anastomosis group 4 from peanut (HG-I), soybean (HG-II), and sugar beet (HG-II) based on the analysis of percent fatty acid composition.

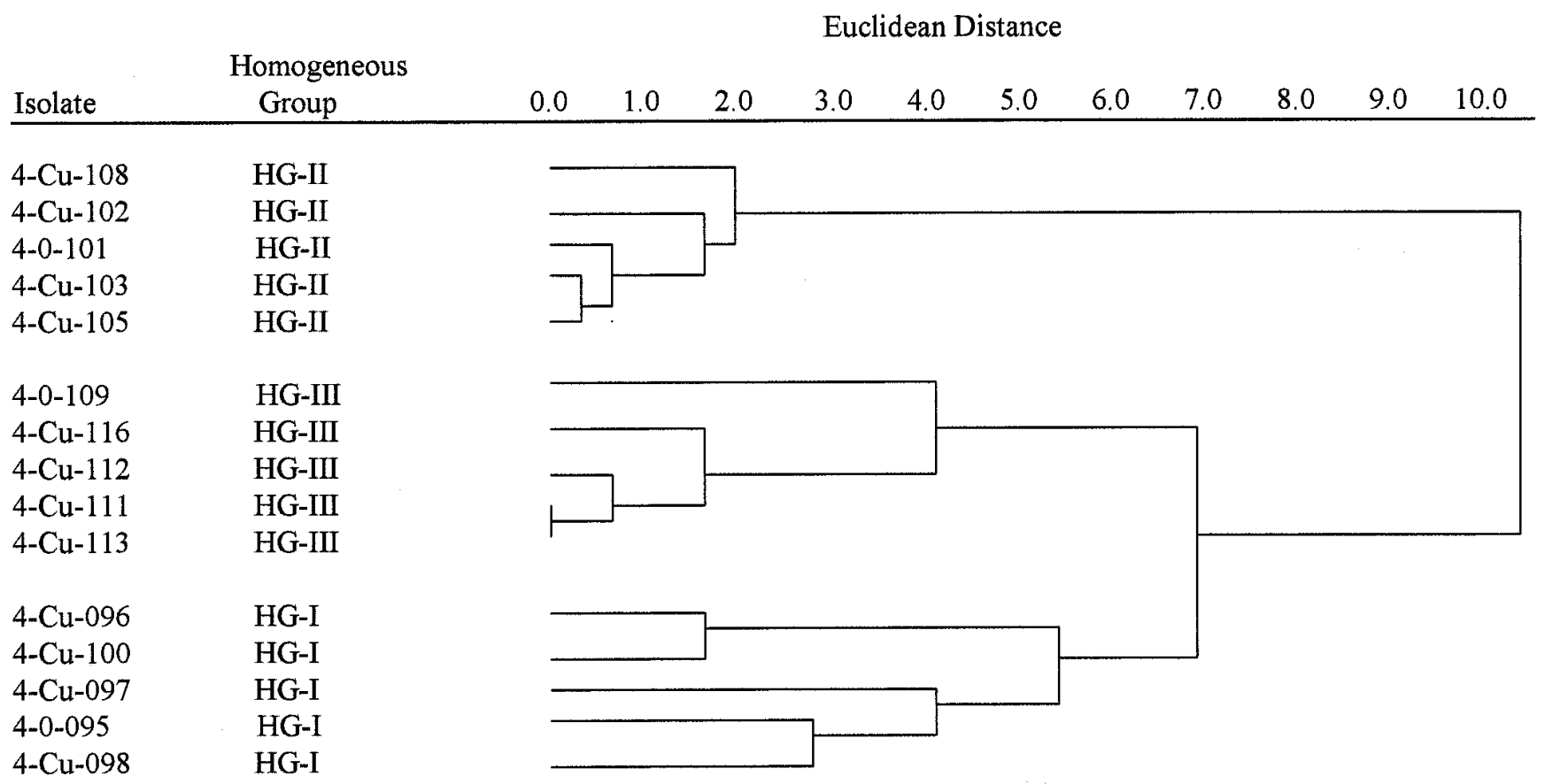

Fig. 3. Dendrogram of isolate library entries of Rhizoctonia solani anastomosis group 4 from cucumber and restriction phenotype (RP) tester strains RP1, RP2, and RP3 based on the analysis of percent fatty acid composition. 
The binomial $R$. practicola has recently been revived (41) to describe isolates formerly assigned to $R$. solani AG-4 (34). Our results support this differentiation, but we call attention to the observation that the practicola-type, as described by Kotila (15), more closely describes only HG-II. In Minnesota, the practicolatype is a serious pathogen of alfalfa, flax, and peas (3). It has been recovered from numerous other crops including soybean, sugar beet, and potato in the Red River Valley of Minnesota and North Dakota. Further north, it causes damping-off in forest tree nurseries (39). It is undoubtably present in other states (including California) (13) and other countries (including Japan) (26-28) but seems ecologically favored in cooler climates (high latitudes or high altitudes). Isolates of HG-I, on the other hand, appear ecologically favored in warmer climates. This ecological specialization was previously reported by Boysen et al. (6).

AG-4 has been reported as a component of the Rhizoctonia complex affecting potato in Peru (4), India (47), and Maine (5). In Minnesota, AG-3 is the predominant cause of stem canker and black scurf (3). Some isolates of AG-4 were recovered in studies involving cropping effects on potatoes in the Red River Valley of North Dakota (Table 1). They were identified in our study as being of the practicola-type (HG-II, RP2). The AG-4 isolates recovered from potatoes in other areas may be of HG-II or of a different HG. Mixtures of groups recovered from the same host plant or field soil has been described for peanuts in Georgia (10) and is reported for cucumber, soybean, and sugar beet in this study.

The isolation of Rhizoctonia spp. from subterranean plant parts frequently includes the recovery of AG-4. Dry bean isolates from
Zaire were characterized as $R$. solani AG-4 (25). Soreshin of cotton (37) and root rot of winter wheat and sugar beet in Texas (38) are also associated with AG-4. To date, these populations have not been characterized as to their homology grouping or their RP. Descriptions of these isolates suggest a closer affinity to HG-I than to the practicola-type (HG-II). These differences could have important implications regarding inoculum survival, dispersion, and the development of effective chemical or cultural control strategies. The relative importance of functional basidial states may vary among different HGs of AG-4.

The relative importance of HG-III is not known, although isolates from this group were pathogenic in other studies $(29,51)$. Isolates of AG-4 exhibit a cultural phenotype consistent with homogeneous grouping although the expression of some characteristics (color, diffusible pigments, sclerotial production, and zonation) varied with age, light, and temperature. In appearance, isolates of HG-III may have been mistakenly identified as HG-II when a collection of HG-I isolates was being studied. Conversely, isolates of HG-III may have been mistakenly assigned to HG-I if they appeared in a collection of HG-II isolates. In future studies, investigators should include examples of each $\mathrm{HG}$ in their comparisons instead of one or more of the available AG-tester isolates (which are all HG-II). Given the intermediate but discontinuous nature of many characteristics, HG-III may represent a stable hybridization of HG-I and HG-II.

The fatty acids identified in isolates characterized as $R$. solani were predominantly the forms characteristic of higher fungi (50). The ratios of palmitic, oleic, and linoleic acids were differential but not unique among collections of isolates classified according

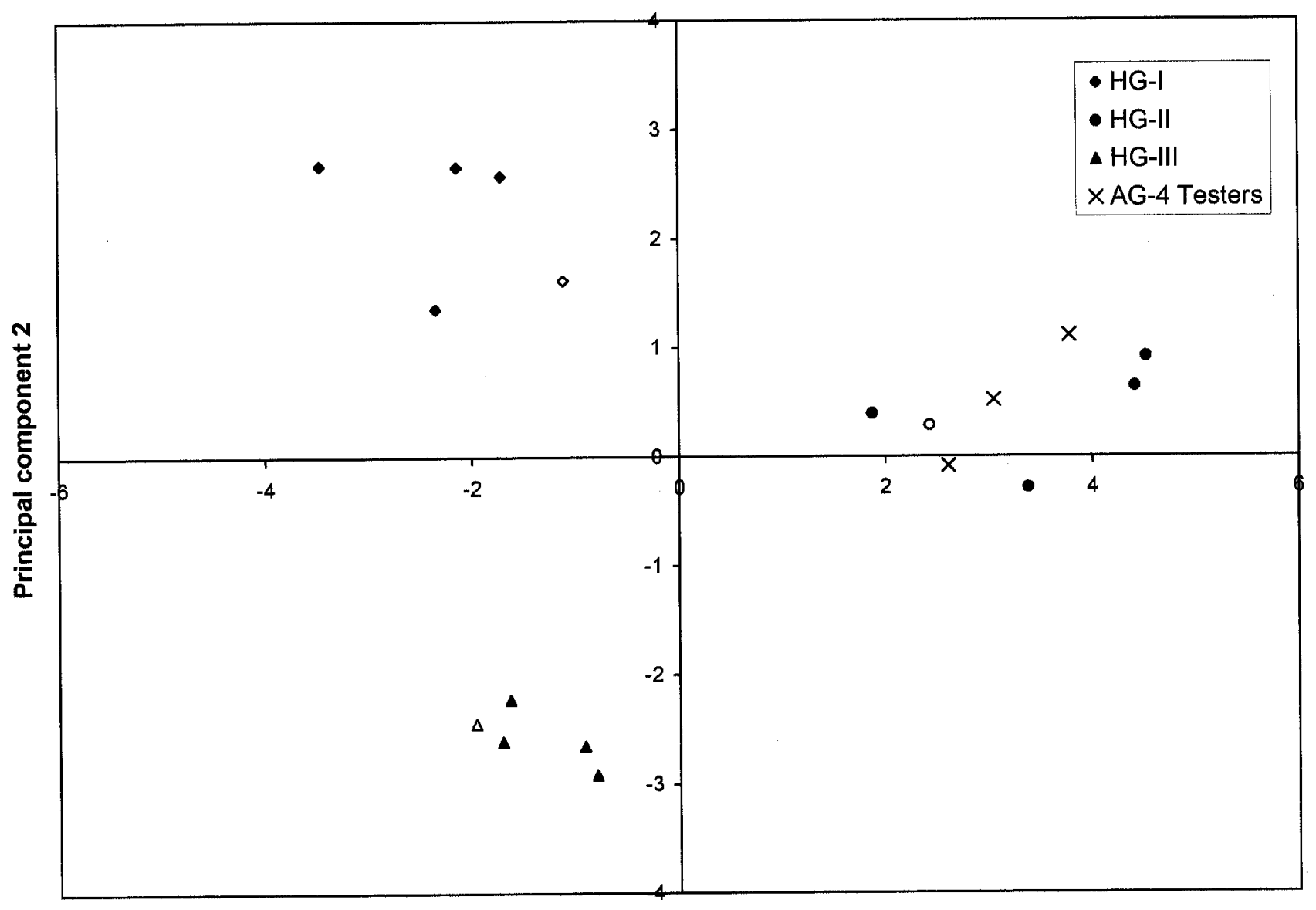

Principal component 1

Fig. 4. Plot of the first two principal components derived from the fatty acid percent compositions (of all detected fatty acids) of Rhizoctonia solani anastomosis group 4 (HG-I, HG-II, and HG-III) isolates from cucumber (shaded symbols), the restriction phenotype (RP) tester strains RP1, RP2, and RP3 (open symbols) and anastomosis tester isolates 4-0-002, 4-0-004, and 4-0-005 (marked as X). 
to AG, cultural morphology, and host. A similarity matrix constructed on the basis of ISGs from AGs 1 to 4 as entries shows closer relationships between certain ISGs than AGs. FAME analysis was not able to differentiate AG-1 IA from AG-1 IB (44),

TABLE 5. Isolates of Rhizoctonia solani anastomosis group 2-1 analyzed in this study

\begin{tabular}{lllc}
\hline Isolate & Host and origin & Isolate reference & Source $^{z}$ \\
\hline $2-1-001$ & Soil, GA & Sumner Rhs145 & 4 \\
2-1-002 & Sugar beet seedling, MN & Windels 10-S-6 & 6 \\
2-1-003 & Sugar beet seedling, MN & Windels 10-S-7 & 6 \\
2-1-004 & Sugar beet seedling, MN & Windels 10-S-8 & 6 \\
2-1-005 & Sugar beet seedling, MN & Windels 10-S-10 & 6 \\
2-1-006 & Sugar beet seedling, MN & Windels 10-S-13 & 6 \\
2-1-007 & Sugar beet seedling, MN & Windels 7-S-44 & 6 \\
2-1-008 & Soil, Australia & Anderson 48, ATCC 44658 & 6 \\
2-1-009 & Pea, Japan & Ogoshi PS-4, ATCC 76168 & 6 \\
2-1-010 & Soil, Australia & Flentje 48, ATCC 44658 & 1 \\
$2-1-011$ & Rice, Japan & Ogoshi HV-1 & 3 \\
$2-1-012$ & Radish, Japan & Kuninaga R123 & 3 \\
2-1-013 & Mat rush, Japan & Butler 455 (Ogoshi BN-1) & 2 \\
$2-1-014$ & Mat rush, Japan & Butler 458 (Ogoshi CI-21) & 2 \\
$2-1-015$ & Potato field soil, Japan & Ogoshi HB618-28 & 5 \\
2-1-016 & Potato field soil, Japan & Ogoshi SH-20 & 5 \\
2-1-017 & Pea, Japan & Ogoshi PS-4, ATCC 76168 & 5 \\
2-1-018 & Anemone, Japan & Ogoshi AN-1 & 5 \\
$2-1-019$ & Sugar beet, Japan & Butler 461 (Ogoshi BV-42) & 2 \\
2-1-020 & Broccoli, MN & Windels 90-27-7 & 6 \\
\hline
\end{tabular}

z 1 = N. A. Anderson, University of Minnesota, St. Paul; 2 = E. E. Butler, University of California, Davis; 3 = D. E. Carling, University of Alaska, Palmer; 4 = R. K. Jones, University of Minnesota, St. Paul; 5 = Z. L. Liu, University of Illinois, Urbana; and $6=$ C. E. Windels, University of Minnesota, NWROC, Crookston. although AG-1 IC isolates were distinct. These differences have been difficult to resolve with molecular techniques. Liu and Sinclair (21) described six subgroups among 61 isolates of AG-1, characterized on the basis of DNA restriction fragment polymorphisms and isozyme analyses. Subgroups A, B, D, and F corresponded to subgroupings we have identified as IA, IA', IB', and IB (Fig. 5). Library entries based on FAME analysis and constructed on that basis showed a very high degree of similarity (overlap) between subgroups IA and IA'B; IA'B and IB'A; and IB'A and IB. Artificial subgroups IA and IB could be constructed that were exclusive. However, if more isolates were analyzed and included in the libraries, the relationship among the four library entries becomes more difficult to resolve as distinct or differential. Based on the analysis of over 90 isolates, FAME library subgroups AG-1 IA and AG-1 IB were not resolvable. It may be that the AG-1 IA and IB groups are recombinant and evolving or that their habitat supports a limited number of stable but closely related subtypes.

Liu and Sinclair (20) examined the relationship between isolates of AG-2 using isozymes and DNA restriction analyses. They identified four subgroups in AG-2 (their group 2E has since been identified as AG-3-tobacco) that correspond to our AG-2 type 1 (Liu's group 2A) and AG-2-2 IIIB (mat rush type or MR; Liu's 2B), AG-2-2 IV (sugar beet root rot type or SBRR; Liu's 2C), and AG-2-2 Turf (large brown patch type or LBP; Liu's 2D). We have previously reported that AG-2-2 isolates causing brace root rot of corn (BRR type; Fig. 5) could not be distinquished from AG-2-2 IIIB by FAME analysis (43) and consider them to be the same subgroup.

Liu et al. (19) reported isolates of AG-2-1 to be more closely related to isolates of AG-3 (their group 2E) than to any of the

\section{Euclidean Distance}
Entry ID's
0.0
2.0
4.0
6.0
8.0
10.0

$\begin{array}{ll}\text { AG-1 } & \text { I A } \\ & \text { I A' B } \\ & \text { I B' A } \\ & \text { I B } \\ & \text { I C }\end{array}$

AG-2-2 III B (MR) Corn (BRR) IV (SBRR) Turf (LBP)

$\begin{array}{ll}\text { AG-3 } & \text { 3-Potato } \\ & \text { 3-Tobacco }\end{array}$

AG-2-1 2-1

$\begin{array}{ll}\text { AG-4 } & \text { HG-I } \\ & \text { HG-III } \\ & \text { HG-II }\end{array}$
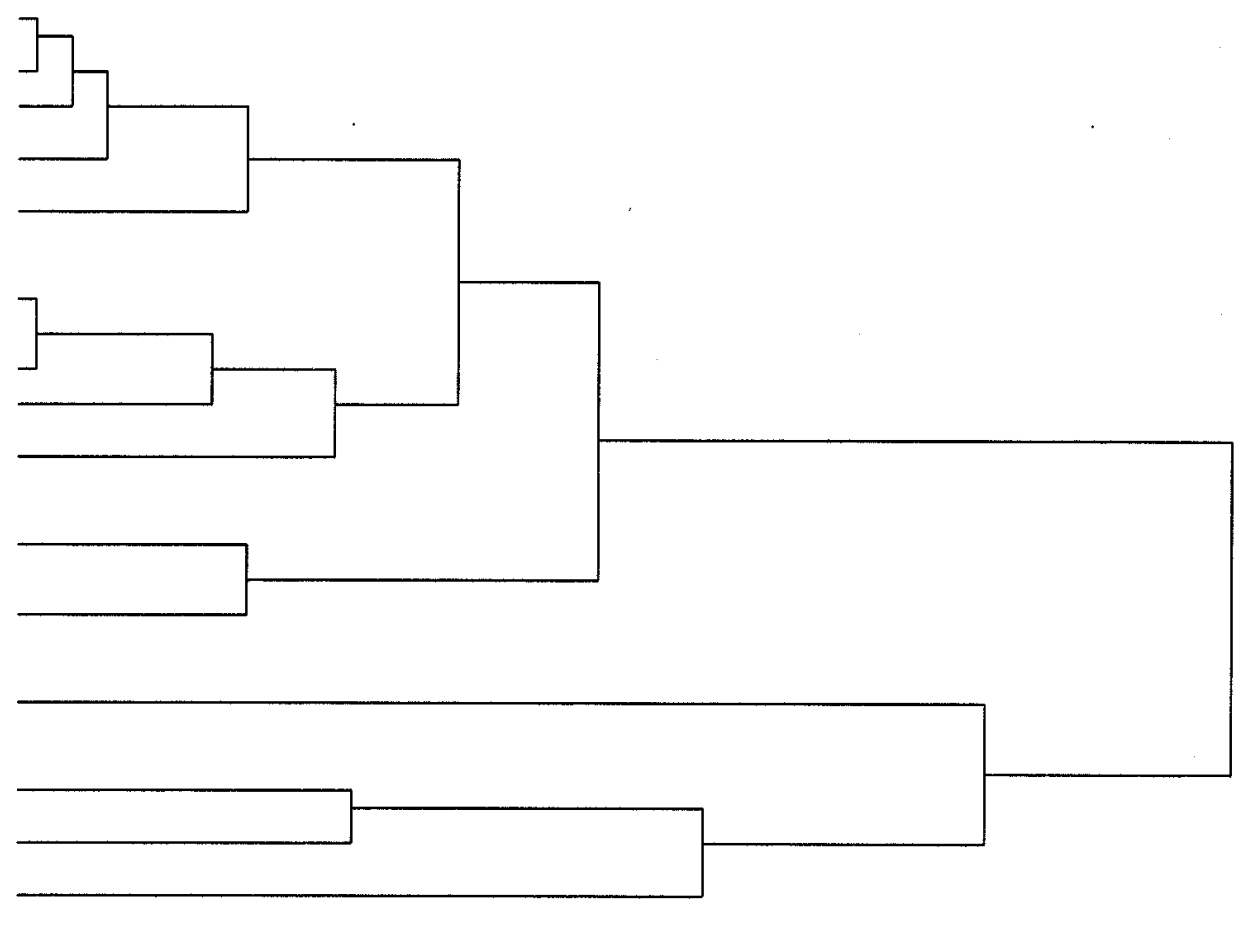

Fig. 5. Dendrogram of subgroup library entries of Rhizoctonia solani anastomosis groups 1, 2-1, 2-2, 3, and 4 based on the analysis of percent fatty acid composition. 
other AG-2-2 subgroups they examined. Based on FAME analysis, we found that AG-2-1 isolates are not closely related to any other subgroup but are more closely related to AG-4 than AG-2-2 (Fig. 5). AG-4, however, is differentiated from AG-1, AG-2-2, and AG-3 at a level that has effectively served to distinguish species from subspecies in bacterial systems (23). Examined independently, the Euclidian distance that separates the AG-4 FAME library entries into three HGs (HG-I, HG-II, and HG-III) are sufficient to support speciation of all three groups. We suggest, however, that the binomial $R$. practicola is only appropriate for HG-II.

Fatty acid analysis has proven useful in differentiating important subgroupings within AG-1 (44), AG-2 (43; this study), AG-3 (45), and AG-4. These subgroups are responsible for significant crop loss throughout the world. Identification of relevant strain groupings within this complex species is paramount to the success of management efforts and requires a thorough understanding of subspecific variation, including that present in AG-4.

\section{ACKNOWLEDGMENTS}

We thank M. A. Cubeta and R. Vilgalys for providing isolates and conducting restriction phenotyping and N. A. Anderson, E. E. Butler, D. E. Carling, N. C. Gudmestad, Z. L. Liu, B. D. Nelson, and C. E. Windels for providing isolates.

\section{LITERATURE CITED}

1. Adams, G. C., Jr. 1988. Thanetephorus cucumeris (Rhizoctonia solani), a species complex of wide host range. Pages 535-552 in: Advances in Plant Pathology, Vol. 6. Genetics of Plant Pathogenic Fungi. G. S. Sidu, ed. Academic Press, New York.

2. Adams, G. C., Jr., and Butler, E. E. 1983. Influence of nutrition on the formation of basidia and basidiospores in Thanatephorus cucumeris. Phytopathology 73:147-151.

3. Anderson, N. A. 1982. The genetics and pathology of Rhizoctonia solani. Annu. Rev. Phytopathol. 20:329-347.

4. Anguiz, R., and Martin, C. 1989. Anastomosis groups, pathogenicity, and other characteristics of Rhizoctonia solani isolated from potatoes in Peru. Plant Dis. 73:199-201.

5. Bandy, B. P., Zanzinger, D. H., and Tavantzis, S. M. 1984. Isolation of anastomosis group 5 of Rhizoctonia solani from potato field soils in Maine. Phytopathology 74:1220-1224.

6. Boysen, M., Borja, M., del Moral, C., Salazar, O., and Rubio, V. 1996. Identification at strain level of Rhizoctonia solani AG4 isolates by direct sequence of asymmetric PCR products of the ITS regions. Curr. Genet. 29:174-181.

7. Brenneman, T. B. 1996. Peanut diseases incited by Rhizoctonia species. Pages 315-320 in: Rhizoctonia Species: Taxonomy, Molecular Biology, Ecology, Pathology and Disease Control. B. Sneh, S. Jabaji-Hare, S. Neate, and G. Dijst, eds. Kluwer Academic Publishers, Dordrecht, the Netherlands.

8. Carling, D. E. 1996. Grouping in Rhizoctonia solani by hyphal anastomosis reaction. Pages 37-47 in: Rhizoctonia Species: Taxonomy, Molecular Biology, Ecology, Pathology and Disease Control. B. Sneh, S. Jabaji-Hare, S. Neate, and G. Dijst, eds. Kluwer Academic Publishers, Dordrecht, the Netherlands.

9. Cubeta, M. A., Abernathy, T., Echandi, E., and Vilgalys, R. 1991. Characterization of anastomosis groups of binucleate Rhizoctonia spp. using restriction analysis of an amplified ribosomal RNA gene. Phytopathology 81:1395-1400.

10. Cubeta, M. A., Gonzalez, D., Vilgalys, R., and Brenneman, T. B. 1992. Characterization of peanut isolates of Rhizoctonia solani from Georgia. (Abstr.) Phytopathology 82:1114.

11. Flentje, N. T. 1956. Studies on Pellicularia filamentosa (Pat.) Rogers I. Formation of the perfect state. Aust. J. Biol. Sci. 17:686-704.

12. Flentje, N. T., Stretton, H. M., and Hawn, E. J. 1963. Nuclear distribution and behavior throughout the life cycles of Thanatephorus, Waitea, and Ceratobasidium species. Aust. J. Biol. Sci. 16:450-467.

13. Houston, B. R. 1945. Culture type and pathogenicity of isolates of Corticium solani. Phytopathology 35:371-393.

14. Jones, R. K., and Belmar, S. B. 1989. Characterization and pathogenicity of Rhizoctonia spp. isolated from rice, soybean, and other crops grown in rotation with rice in Texas. Plant Dis. 73:1004-1010.

15. Kotila, J. E. 1929. A study of a new spore-forming Rhizoctonia, Corticium practicola. Phytopathology 19:1059-1099.
16. Kuninaga, S., Natsuaki, T., Takeuchi, T., and Yokosawa, R. 1997. Sequence variation of the rDNA ITS regions within and between anastomosis groups in Rhizoctonia solani. Curr. Genet. 32:237-243.

17. Kuninaga, S., and Yokosawa, R. 1984. DNA base sequence homology in Rhizoctonia solani Kuhn. IV. Genetic relatedness within AG-4. Ann. Phytopathol. Soc. Jpn. 50:322-330.

18. Lewis, J. A., and Papavizas, G. C. 1980. Integrated control of Rhizoctonia fruit rot of cucumber. Phytopathology 70:85-89.

19. Liu, Z. L., Domier, L. L., and Sinclair, J. B. 1993. ISG-specific ribosomal DNA polymorphism of the Rhizoctonia solani complex. Mycologia 85:795-800.

20. Liu, Z. L., and Sinclair, J. B. 1992. Genetic diversity of Rhizoctonia solani anastomosis group 2. Phytopathology 82:778-787.

21. Liu, Z. L., and Sinclair, J. B. 1993. Differentiation of intraspecific groups within anastomosis group 1 of Rhizoctonia solani using DNA internal transcribed spacer and isozyme comparisons. Can. J. Plant Pathol. 15:272-280.

22. Matsuyama, N., Moromizato, Z., Ogoshi, A., and Wakimoto, S. 1978. Grouping Rhizoctonia solani Kuhn with non-specific esterase zymograms. Ann. Phytopathol. Soc. Jpn. 44:652-658.

23. Mendala, B. 1990. A user generated "custom" library for the MIS. Technical Note 103, Microbial ID, Inc. (MIDI), Newark, DE.

24. Mordue, J. E. M., Currah, R. S., and Bridge, R. D. 1989. An integrated approach to Rhizoctonia taxonomy: Cultural, biochemical and numerical techniques. Mycol. Res. 92:78-90.

25. Muyolo, N. G., Lipps, P. E., and Schmitthenner, A. F. 1993. Anastomosis grouping and variation in virulence among isolates of Rhizoctonia solani associated with dry bean and soybean in Ohio and Zaire. Phytopathology $83: 438-444$

26. Naiki, T., and Ui, T. 1981. Rhizoctonia root rot of bean, soybean, and adzuki bean seedlings. Mem. Fac. Agric. Hokkaido Univ. 12:262-269.

27. Naito, S., Sugimoto, T., Yamiguchi, T., and Fujisawa, I. 1975. Anastomosis groupings of Rhizoctonia solani Kuhn isolated from diseased sugar beet seedling. Res. Bull. Hokkaido Natl. Agric. Exp. Stn. 111:25-35.

28. Naito, S., Yamiguchi, T., Sugimoto, T. 1974. Grouping of isolates of Rhizoctonia solani Kuhn from root rot of sugar beets. Res. Bull. Hokkaido Natl. Agric. Exp. Stn. 108:45-53.

29. Nelson, B., Helms, T., Christianson, T., and Kural, I. 1996. Characterization and pathogenicity of Rhizoctonia from soybean. Plant Dis. 80:74-80.

30. Ogoshi, A. 1985. Anastomosis and intraspecific groups of Rhizoctonia solani and binucleate Rhizoctonia. Fitopatol. Bras. 10:371-390.

31. Ogoshi, A. 1987. Ecology and pathogenicity of anastomosis and intraspecific groups of Rhizoctonia solani Kuhn. Annu. Rev. Phytopathol. 25:125-143.

32. Ogoshi, A. 1996. Introduction-The genus Rhizoctonia. Pages 1-9 in: Rhizoctonia Species: Taxonomy, Molecular Biology, Ecology, Pathology and Disease Control. B. Sneh, S. Jabaji-Hare, S. Neate, and G. Dijst, eds. Kluwer Academic Publishers, Dordrecht, the Netherlands.

33. Parmeter, J. R., Jr., Sherwood, R. T., and Platt, W. D. 1969. Anastomosis grouping among isolates of Thanatephorus cucumeris. Phytopathology 59:1270-1278.

34. Parmeter, J. R., Jr., and Whitney, H. S. 1970. Taxonomy and nomenclature of the imperfect state. Pages 7-19 in: Biology and Pathology of Rhizoctonia solani. J. R. Parmeter Jr., ed. University of California Press, Berkeley.

35. Reynolds, M., Weinhold, A. R., and Morris, T. J. 1983. Comparison of anastomosis groups of Rhizoctonia solani by polyacrylamide gel electrophoresis of soluble proteins. Phytopathology 73:903-906.

36. Ridgeway, R. 1912. Color standards and color nomenclature. A. Hoen \& Co., Baltimore, MD.

37. Rothrock, C. S. 1996. Cotton diseases incited by Rhizoctonia solani. Pages 269-277 in: Rhizoctonia Species: Taxonomy, Molecular Biology, Ecology, Pathology and Disease Control. B. Sneh, S. Jabaji-Hare, S. Neate, and G. Dijst, eds. Kluwer Academic Publishers, Dordrecht, the Netherlands.

38. Rush, C. M., Carling, D. E., Harveson, R. M., and Mathieson, J. T. 1994. Prevalence and pathogenicity of anastomosis groups of Rhizoctonia solani from wheat and sugar beets in Texas. Plant Dis. 78:349-352.

39. Saksena, H. K., and Vaartaja, O. 1961. Taxonomy, morphology and pathogenicity of Rhizoctonia species from forest nurseries. Can. J. Bot. 39:626-647.

40. Sherwood, R. T. 1969. Morphology and physiology in four anastomosis groups of Thanatephorus cucumeris. Phytopathology 59:1924-1929.

41. Sneh, B., Burpee, L., and Ogoshi, A. 1991. Identification of Rhizoctonia Species. The American Phytopathological Society, St. Paul, MN.

42. Stevens Johnk, J., and Jones, R. K. 1992. Determination of whole-cell fatty acids in isolates of Rhizoctonia solani AG-1 IA. Phytopathology 82:68-72.

43. Stevens Johnk, J., and Jones, R. K. 1993. Differentiation of populations of AG-2-2 of Rhizoctonia solani by analysis of cellular fatty acids. 
Phytopathology 83:278-283.

44. Stevens Johnk, J., and Jones, R. K. 1994. Comparison of whole-cell fatty acid compositions in intraspecific groups of Rhizoctonia solani AG-1. Phytopathology 84:271-275.

45. Stevens Johnk, J., Jones, R. K., Shew, H. D., and Carling, D. E. 1993. Characterization of populations of Rhizoctonia solani AG-3 from potato and tobacco. Phytopathology 83:854-858.

46. Sumner, D. R., and Smittle, D. A. 1976. Etiology and control of fruit rot of cucumber in single harvesting for pickles. Plant Dis. Rep. 60:304-307.

47. Suresh, K., and Mall, S. 1982. Anastomosis groups of potato isolates of Rhizoctonia solani in India. Mycologia 74:337-338.

48. Vilgalys, R. 1988. Genetic relatedness among anastomosis groups in
Rhizoctonia solani as measured by DNA/DNA hybridization. Phytopathology 78:698-702.

49. Vilgalys, R., and Cubeta, M. A. 1994. Molecular systematics and population biology of Rhizoctonia. Annu. Rev. Phytopathol. 32:135-155.

50. Weete, J. D. 1980. Lipid Biochemistry of Fungi and Other Organisms. Plenum Press, New York.

51. Windels, C. E., and Nabben, D. J. 1989. Characterization and pathogenicity of anastomosis groups of Rhizoctonia solani isolated from Beta vulgaris. Phytopathology 79:83-88.

52. Woodard, K. E., and Jones, B. L. 1983. Soil populations and anastomosis groups of Rhizoctonia solani associated with peanut in Texas and New Mexico. Plant Dis. 67:385-387. 